\title{
A compilation of national plans, policies and government actions for rare diseases in 23 countries
}

\author{
Neil Khosla*, Rodolfo Valdez \\ Division of Human Development and Disability, National Center on Birth Defects and Developmental Disabilities, Centers for \\ Disease Control and Prevention, Atlanta, GA, USA.
}

\begin{abstract}
Summary Previous studies have focused on the comparison of specific laws among multiple countries and regions; for example, laws related to facilitating treatments with orphan drugs or laws seeking to address the multiple needs of patients with rare diseases. The purpose of this scoping review is to examine and compare published reports on national plans, polices and legislation related to all rare diseases in different countries. We also examine strategies or programs that countries may have for these diseases. Articles were obtained from journals and books published between January 1, 2000, through December 15, 2017. Reports from the grey literature (documents issued by government and private organizations) were included if they were available on the internet. The databases used were Google and Google Scholar, PubMed, and the websites of Orphanet and the National Organization for Rare Disorders (NORD). We obtained information on 23 countries. Among these countries, the way in which rare diseases were defined varied from having similar definitions to no definition. Multinational programs supported by common or similar laws are likely to have a greater impact on rare diseases than single country programs.
\end{abstract}

Keywords: Rare disease legislation, program, strategy

\section{Introduction}

In the United States (US), a rare disease is one affecting fewer than 200,000 individuals at a given time. Despite their individual low frequencies, the large number of rare diseases (estimated between 6,000 and 8,000) makes them collectively common $(1,2)$. Worldwide, rare diseases affect approximately 400 million people (3). About $80 \%$ of these diseases have a genetic origin and their severity ranges from minor to life threatening $(3,4)$. Because of their genetic or congenital origin, numerous rare diseases have a serious impact on health starting at birth or early childhood and represent a major challenge for patients, caregivers, physicians, healthcare providers, and society in general. The financial impact

Released online in J-STAGE as advance publication November 25, 2018.

*Address correspondence to:

Mr. Neil Khosla, Division of Human Development and Disability, National Center on Birth Defects and Developmental Disabilities, Centers for Disease Control and Prevention, 1600 Clifton Rd. NE, MS (E-88), Atlanta, GA 30333, USA.

E-mail: neilkhosla87@yahoo.com of rare diseases is also significant $(3,5,6)$. For instance, the medical expenses for adults with spina bifida could be three to six times as high as that for adults without the disease (7). In 2014, the average annual cost in the US for orphan drugs developed for rare diseases was $\$ 137,782$ per patient (8). This financial impact noticeably increases the overall cost of managing a rare disease for which orphan drugs are prescribed. Furthermore, the quality of life for patients with a rare disease may decline with age (6). A Swedish study showed that, in a ten-year period, the proportion of individuals with adult forms of muscular dystrophy able to walk without assistive devices decreased from $91 \%$ to $52 \%(9)$. The age range of this group was 16 to 65 years (9).

Rare diseases also affect physicians and the healthcare system in general. The scarcity of knowledge, guidelines, and training on rare diseases makes the diagnosis and management of these diseases difficult $(3,5)$. For example, a survey conducted among caregivers of patients with a rare disease in the US and the United Kingdom (UK) found that these patients had often received a misdiagnosis from multiple physicians. It was not until approximately three years after the first misdiagnosis that patients with a rare disease received a 
correct diagnosis ( 6 ). This delay in diagnosis adds to the costs of the disease incurred by patients, their caregivers, and the healthcare system. Further, patients with a rare disease may not only need to see multiple physicians to get a correct diagnosis, they may also need care from multiple practitioners. This can also present a challenge. A majority of physicians in the US (76\%) and in the UK $(88 \%)$ reported having difficulties coordinating care with other providers who are managing the same patient with a rare condition $(6)$.

In addition to the challenges of accurately diagnosing rare diseases and assessing the impact these diseases have on patients and their caregivers, there is the challenge of how to reach a patient population that is few in number and widely scattered geographically. The typical public health approach, designed for diseases that are either common or tend to cluster, might not be relevant for rare diseases. Hence, a frequently used strategy to support public health approaches aimed at reducing the burden of rare diseases is by government action; for example, the US has used this approach extensively: in 1983 the US Congress passed the Orphan Drug Act, its first major federal statute dedicated to rare diseases. This law encouraged the production of orphan drugs (drugs developed to treat rare diseases) by providing financial incentives to pharmaceutical industries to offset the potential losses of marketing drugs to such a small market (10). Further, in 2001, the US Congress passed the "Muscular Dystrophy Community Assistance, Research and Education Amendments of 2001" (MD CARE Act) (11), which promoted surveillance and research, improved screening techniques, fostered collaboration among muscular dystrophy centers, and stimulated the development of educational programs for all types of muscular dystrophy. Research that resulted from the MD CARE Act included early detection, diagnosis, prevention, and treatment for muscular dystrophy (12).

Finally, a government may create laws aimed at reducing the occurrence of rare diseases that have a preventable cause, such as neural tube defects (NTDs). In 1998, a regulation issued by the US Food and Drug Administration (FDA) went into effect that mandated the addition of folic acid to cereal grain products labeled as enriched in the US (13). The objective of this regulation was to provide women with an avenue for increasing dietary intake of folic acid, which can help prevent NTDs. As a result of this regulation, just over 1,300 more babies were born without a NTD each year from 1999 through 2011 (14). To date, mandatory folic acid fortification of grain cereals now exist in 86 countries (15).

The use of legal means to benefit patients with rare diseases has also been underway in the European Union (EU). The academic literature shows the EU has created a unified approach toward the management of rare diseases through the use of regulations, directives, recommendations, and communications (16-21). This approach seeks to make rare diseases more visible by identifying and coding them; by encouraging the development of national plans to ensure equal access to health care for people with rare diseases; and by promoting regional support to activities such as research, financial incentives, screening, and orphan drug development.

In sum, the literature demonstrates that law-based interventions aimed at rare diseases in the US and Europe have encouraged the production of orphan drugs, accommodated health care systems to the needs of patients with rare diseases, and promoted research to prevent and ameliorate the impact of these diseases on affected individuals and populations. The purpose of this study is a scoping review exploring the academic literature for the past 18 years, searching for publications in English that refer to national plans, policies and legislation on rare diseases from countries around the world. This review also includes strategies or programs for rare diseases from these countries. As a result, we will compile similarities and differences reported in the literature among law-based national approaches that focus on rare diseases.

\section{Literature Search Strategy}

First, we searched repositories of biomedical literature for articles and book chapters describing national plans, policies or laws for rare diseases in general. Second, we complemented the previous search by searching the same repositories for countries with specific strategies or programs for rare diseases that were national or multi-national in scope. Third, we searched the grey literature for reports about any of the items searched in the previous two steps. Our search was limited to publications and documents in English, or in other languages with complete abstracts in English, that were published from January 1, 2000 through December 15, 2017. In our search we used only keywords in English and we collected three types of documents: 1) all in English; 2) with a complete abstract in English but the rest of the document in another language; and 3) websites in English. The search engines we used were Google or Google Scholar, PubMed, Orphanet, and the database of the National Organization for Rare Disorders (NORD). The search terms, alone or combined, included "rare disorder," "rare disease," "national plan," "legislation," "policy," "strategy," and "program." We then examined abstracts, book chapters, websites, and reports resulting from the searches to assess their relevance to our objectives. We retrieved a document for inclusion in the study only if it described a plan, policy, legislation, strategy, or program for rare diseases at a national or multi-national scale. We excluded from this review documents that appeared to be duplicates, that had no publication date; that reported unpublished results 
or personal communications, and conference abstracts. Figure 1 shows the flow diagram of our search. Finally, we organized the results of our review by country within large geographic regions and highlighted the characteristics of the national approaches to rare diseases that we found in the literature.

\section{Results}

Our exploratory search yielded 19,179 potentially relevant publications for the period under study. After applying the selection criteria (Figure 1), 56 publications qualified for our compilation: 37 from scholarly journals, 17 from the grey literature, and two books. The publications originated from four regions or their combinations as follows: 8 from Canada and the US, 19 from Europe, 13 from Asia-Pacific, 4 from Latin America, and 12 from multi-country regions (Figure 2).
Regarding these combined regions, two publications included Europe and Latin America, nine included Canada, the US, Europe and the Asia-Pacific region, and two included Canada, the US and Europe. Tables 1-4 present the rare disease definitions, plans, legislation, programs, and strategies by region and country. Of note, since the term rare refers to diseases of very low frequency in a population, the definitions of this term are based on the prevalence rather than the attributes of a disease. According to the literature, some countries use total number of cases in a population as a threshold to define a rare disease, while other countries use proportions.

\subsection{Canada and the US}

Table 1 reports the results for Canada and the US. Unlike the US, Canada defines rare diseases by the

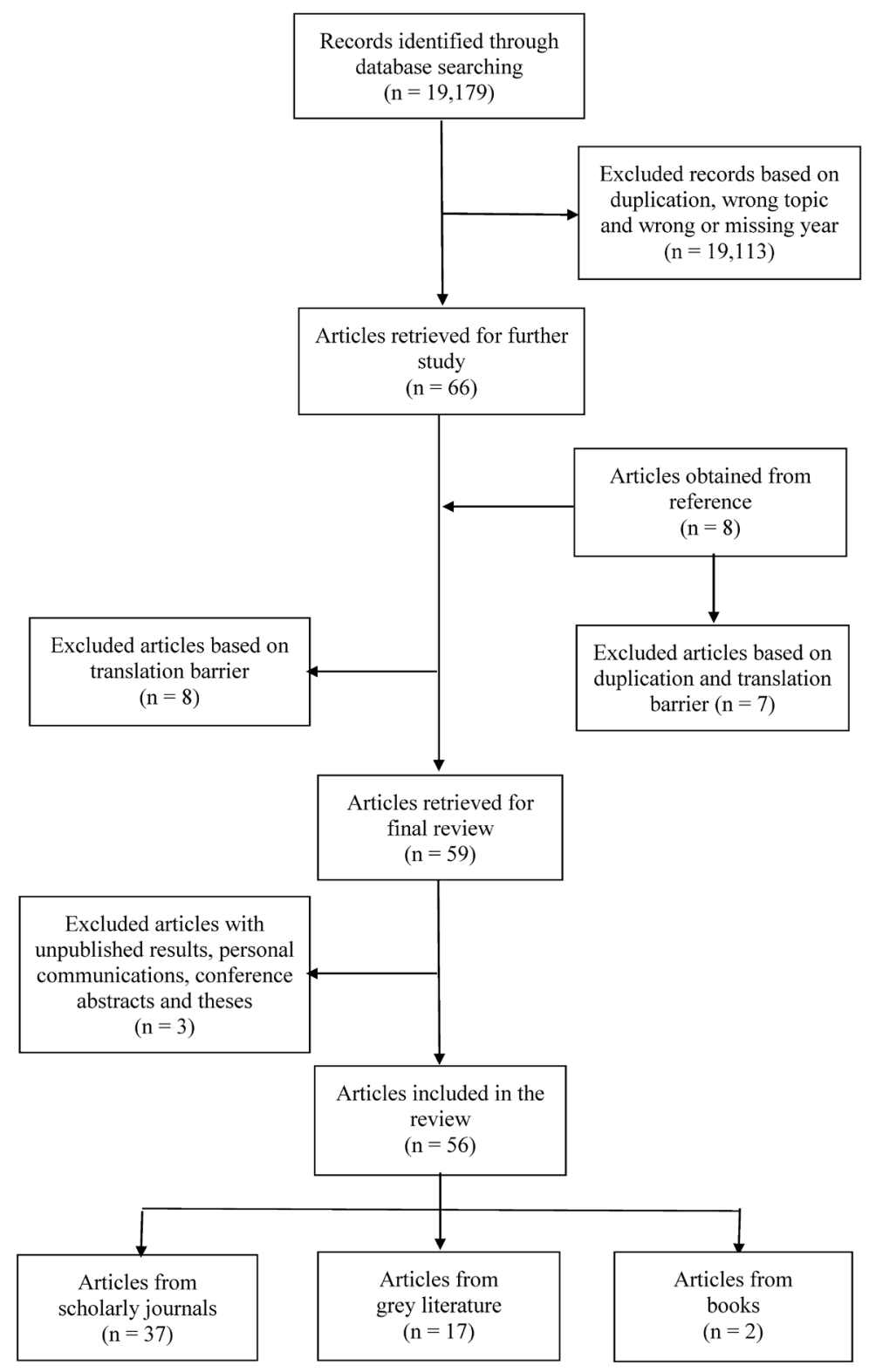

Figure 1. Flow diagram of the search strategy. 


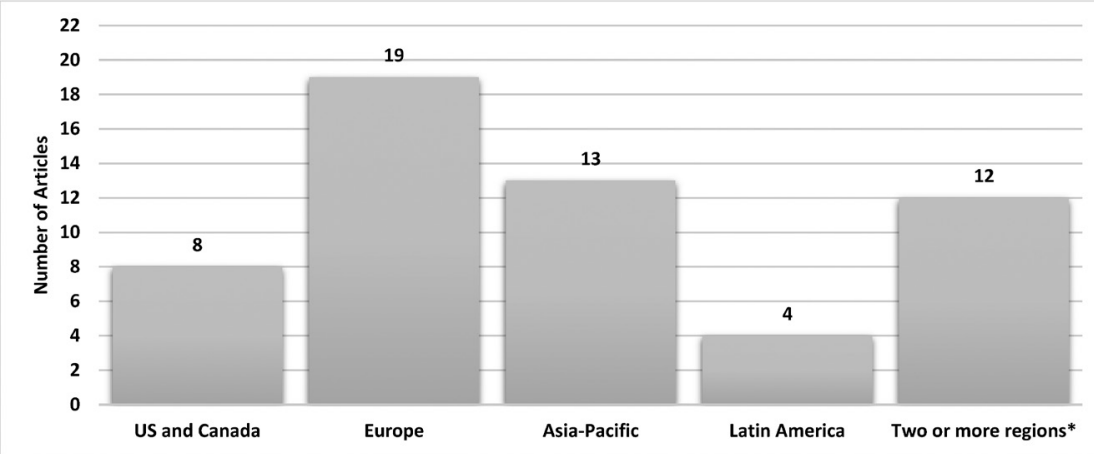

Figure 2. Number of rare disease articles from different countries, by region.*indicates that the documents described a plan, policy, legislation, strategy, or program for multiple regions.

Table 1. Rare disease plans, legislation, programs or strategies in Canada and the United States

\begin{tabular}{lccccc}
\hline Country & $\begin{array}{c}\text { Definition of } \\
\text { rare disease }\end{array}$ & $\begin{array}{c}\text { National } \\
\text { Plan }\end{array}$ & Legislation & $\begin{array}{c}\text { Program } \\
\text { or Strategy }\end{array}$ & Highlights \\
\hline $\begin{array}{l}\text { Canada } \\
23,25)\end{array}$ & $\begin{array}{c}\text { Fewer than } 5 \\
\text { cases per 10,000 } \\
\text { people (draft) }\end{array}$ & No & No & Yes & $\begin{array}{l}\text { Health Canada's Special Access Program: Provides access to several } \\
\text { orphan drugs for patients with rare diseases. } \\
\text { Orphan Drug Framework: Promises to increase lifecycle of orphan drugs, } \\
\text { work with other countries with an established orphan drug framework, } \\
\text { and to improve access to orphan drugs and facilitate research. } \\
\text { The Canadian Organization for Rare Disorders (CORD) } 5 \text { Strategic } \\
\text { Goals for Canada's Rare Disease Strategy: Detection and prevention, } \\
\text { timely, equitable and evidence-informed care, community support, access } \\
\text { to promising therapies and research. }\end{array}$
\end{tabular}

United States $\quad$ Fewer than $\quad$ No $\quad$ Yes $\quad$ Yes Orphan Drug Act (1983): Regulatory fee waivers, 50\% tax credit in $(1-3,5,8,10,25, \quad 200,000$ cases clinical expenditure, grants for clinical research, development of medical $35,39,49-57)$ devices and medical food, protocol assistance, accelerated review if indication permits, and 7 year market exclusivity.

Rare Disease Act (2002): Established the Office of Rare Diseases. Increased federal funding for the development of treatments for rare diseases.

National Institute of Health Research Programs: Translational research on rare diseases and emphasis on diagnostics and interventions (e.g.: Genetic and Rare Disease Information Center).

proportion of cases in a population (22). The reports that we found indicate that Canada has no national plan or specific legislation on rare diseases $(10,22)$, the Minister of Health put forward a draft for an orphan drug regulatory framework in 2012 (22,23). According to a previous report, this framework would rely on existing Canadian laws that regulate health products and food, including the regulation of labelling and packaging, clinical trials, and manufacturing and marketing of these products; however, this framework has yet to be implemented (24). Also, the Canadian Organization for Rare Disorders (CORD) has provided five strategic goals for a Canadian Rare Disease Strategy (23).

About 35 years ago, the US passed its first major law on orphan drugs, known as the Orphan Drug Act, aimed at stimulating the production of medicines for rare diseases by offering pharmaceutical companies research grants, tax credits, fee waivers, and a sevenyear market exclusivity for approved medications (10). Other pieces of legislation in the US include the Rare
Disease Act, which established the Office of Rare Diseases at the National Institutes of Health (NIH) (10) and legislation for single rare disease entities, such as the MD Care Act (11).

\subsection{Europe}

For Europe, our exploratory search resulted in a handful of publications from the subset of countries that form the EU. Multiple articles, spanning a number of years, demonstrate that Europe has an integrated, multi-country approach to rare diseases (Table 2). The publications found report that all 28 countries in this union have a common definition of rare disease, based on the proportion of cases in the population, and their rare disease activities operate under multinational legislation called the Orphan Medicinal Product Regulation (EC) No. 141/2000. This regulation seeks to stimulate research and to promote the development of orphan drugs to treat patients with rare diseases (1720). Europe also has developed the European Project 
Table 2. Rare disease plans, legislation, programs or strategies in Europe

Within Europe, the European Union (EU) has adopted a common definition of a rare disease (Fewer than 5 cases per 10,000 people) and has a common legislation [Regulation (EC) No. 141/2000 (1999): Regulatory fees reduced or waived, access to centralized procedures, and protocol assistance. Member states implemented measures to encourage the development of orphan medicinal products. Tax credits are managed by member states. Market exclusivity for 10 years; 6 years if drug criteria not met.] Each member state has additional legislation $(1-5,8,10,18-21,39,51,57,59,60)$.

\begin{tabular}{|c|c|c|c|}
\hline Country & $\begin{array}{l}\text { National Legislation } \\
\text { Plan }\end{array}$ & $\begin{array}{l}\text { Program } \\
\text { or Strategy }\end{array}$ & Highlights \\
\hline
\end{tabular}

\begin{tabular}{lllll}
\hline $\begin{array}{l}\text { Bulgaria } \\
(1,16,17,25-27,66)\end{array}$ & Yes $\quad$ Yes $\quad$ Yes $\quad \begin{array}{l}\text { National Plan (2009-2013): To deliver prevention, diagnostics, treatment and } \\
\text { rehabilitation to rare disease patients. }\end{array}$
\end{tabular}

France $\quad$ Yes $\quad$ Yes $\quad$ Yes First National Plan (2005-2008): To increase knowledge on the epidemiology of rare $(1,3,16,17,25-28$, diseases, recognize the specificity of rare diseases, develop information on rare diseases $53,61) \quad$ for patients, healthcare professionals and the general public, train healthcare professionals for better identification of this disease, organize screening and access to diagnostic tests, continue efforts in favor of orphan drugs, meet the specific requirements for social services for patients with rare diseases, promote research on rare disease, and develop national and European partnership.

Second National Plan (2011-2014): Increase quality of patient care with the use of reference centers and telemedicine, develop research on rare disease such as translational clinics and therapeutic research, and increase European and global cooperation

\begin{tabular}{|c|c|c|c|c|}
\hline $\begin{array}{l}\text { Germany } \\
(1,16,17,25-27,63)\end{array}$ & Yes & Yes & Yes & $\begin{array}{l}\text { "Nationales Aktionsbündnis für Menschen mit Seltenen Erkrankungen" (NAMSE): There } \\
\text { were } 52 \text { policy proposals for action. Action fields for these proposals include care/centers/ } \\
\text { networks, research, diagnostics, information management, patient orientation, registries, } \\
\text { and implementation and future development. }\end{array}$ \\
\hline
\end{tabular}
$\begin{aligned} & \text { Greece } \\ & (1,16,17)\end{aligned} \quad$ Yes $\quad$ Yes $\quad$ Yes $\quad \begin{aligned} & \text { National Plan (2008-2012): Includes early diagnosis, medical treatment, prevention, } \\ & \text { research, education, and partnership and co-operation strategies. }\end{aligned}$

\begin{tabular}{|c|c|c|c|c|}
\hline $\begin{array}{l}\text { Italy } \\
(1,16,17,26-28, \\
58,64)\end{array}$ & $\begin{array}{c}\text { Yes } \\
\text { (Draft) }\end{array}$ & Yes & Yes & $\begin{array}{l}\text { Ministerial Decree } n .279 / 2001 \text { : Provides a price exemption for care on certain rare } \\
\text { diseases; contemplates setting up a network of centers for rare disease patients identified } \\
\text { through their experience, activities and services for these patients. The decree also } \\
\text { contains regulations for a national registry. }\end{array}$ \\
\hline $\begin{array}{l}\text { Portugal } \\
(1,16,17,26,27)\end{array}$ & Yes & Yes & Yes & $\begin{array}{l}\text { National Plan (2008-2015): To determine the needs of rare disease patients and their } \\
\text { families and to improve the quality and equity of healthcare services. }\end{array}$ \\
\hline $\begin{array}{l}\text { Spain } \\
(1,16,17,26,27,65)\end{array}$ & Yes & Yes & Yes & $\begin{array}{l}\text { National Plan (2010): Includes information on rare disease (resources, registers and } \\
\text { coding plus classification), prevention and early detection, healthcare, therapies, integrated } \\
\text { health and social care, research and training. Centers of expertise provide services and } \\
\text { focus on the needs of rare disease patients. Reference centers promise access to healthcare } \\
\text { for these patients. }\end{array}$ \\
\hline $\begin{array}{l}\text { United Kingdom } \\
\text { (UK) } \\
(1,17,25-28,62)\end{array}$ & $\begin{array}{l}\text { Yes (Plan } \\
\text { approved } \\
\text { for } 4 \text { UK } \\
\text { states) }\end{array}$ & Yes & Yes & $\begin{array}{l}\text { UK strategy for rare disease: Examines patients and their families. Includes empowering } \\
\text { rare disease patients, identifying and preventing these diseases (screening and carrier } \\
\text { testing), diagnosis and early intervention, coordination of care (specialist centers) and } \\
\text { research. Strategy will continue to work with other countries with rare disease. }\end{array}$ \\
\hline
\end{tabular}

for Rare Disease National Plan (EUROPLAN) to facilitate the creation of national plans in the region $(3,16,19-21,25)$. These plans are defined as official public health strategies accepted by a government with explicit priorities, actions, a timetable and a budget (16). Research on rare diseases in Europe is supported by The Seventh Framework Program (FP7), which is a program that funds medium- to large-sized collaborative research projects $(19,20,25)$. In addition, free, shortterm access to orphan products is accomplished through Compassionate Use Programs (CUPs) in Member States (26-28), with some exceptions such as Greece $(26,27)$. For the period of our search, eight countries from the EU issued publications related to their national plans, legislation, and programs or strategies for rare diseases. These results are summarized in Table 2.

\subsection{Asia-Pacific}

Our search found documents that show evidence of legislative activity on rare diseases in seven countries of the Asia-Pacific region (Table 3). In the articles reviewed, the definition of a rare disease varies widely among these countries. Only Singapore and South Korea share a definition. Six of the countries are reported to have legislation addressing rare diseases, yet none appear to have a national plan for these diseases. All seven countries were shown to have programs or strategies aimed at rare diseases. Our review found that Australia has at least two regulatory programs, derived from healthcare laws enacted by the parliament: the Orphan Drug Program, which provides financial and marketing incentives for drug makers 
Table 3. Rare disease plans, legislation, programs or strategies in Asia-Pacific Countries

\begin{tabular}{|c|c|c|c|c|c|}
\hline Country & $\begin{array}{l}\text { Definition of } \\
\text { rare disease }\end{array}$ & $\begin{array}{l}\text { National } \\
\text { Plan }\end{array}$ & Legislation & $\begin{array}{c}\text { Program } \\
\text { or Strategy }\end{array}$ & Highlights \\
\hline $\begin{array}{l}\text { Australia } \\
(1-3,10,29,32 \text {, } \\
35,39,51)\end{array}$ & $\begin{array}{l}\text { Fewer than } \\
2,000 \text { cases. }\end{array}$ & No & Yes & Yes & $\begin{array}{l}\text { Orphan Drug Program (1998): Regulatory fee waivers, no grants or } \\
\text { tax credits, protocol assistance, and priority review. } 5 \text { year market } \\
\text { exclusivity. }\end{array}$ \\
\hline $\begin{array}{l}\text { China } \\
(1,25,30-32, \\
35,71)\end{array}$ & $\begin{array}{l}\text { Prevalence lower } \\
\text { than } 1 / 500,000 \\
\text { (disorder) or incidence } \\
\text { lower than } 1 / 10,000 \\
\text { (newborns). Definition } \\
\text { not agreed by patient } \\
\text { organizations. }\end{array}$ & No & No & Yes & $\begin{array}{l}\text { China pilot project: to provide and use guidelines, create registries } \\
\text { and encourage molecular testing for rare diseases. This project seeks } \\
\text { to build relationships with collaborative networks, clinicians and } \\
\text { patient organizations. } \\
\text { "Rare Disease Clinical Cohort Study": Research program will } \\
\text { establish the unified National Registry System of China in } 2020 \text { and } \\
\text { large cohort study will examine classification, diagnosis, treatment } \\
\text { and prognosis for rare diseases. }\end{array}$ \\
\hline
\end{tabular}

\section{Japan
$(1-3,8,10,32$, \\ $35,39,51,57$}

67-69)

Fewer than $\quad$ No $\quad$ Yes
50,000 cases.

\begin{abstract}
Pharmaceutical Affairs Law (1993): Regulatory fee waivers, clinical and non-clinical study grants, $15 \%$ tax credits and up to $14 \%$ tax reduction ( $6 \%$ tax reductions for preclinical research). Protocol assistance and fast track approval. 10 year market exclusivity.

"Revision of Measures to Combat Intractable Diseases": Strategies stressed treatment and improve care for those affected, tools to reimburse medical costs, and promote participation.

Specified Disease Treatment Program: Focused on funding to encourage research and orphan drug development
\end{abstract}

Philippines

$(32,33,70)$

Singapore

$(1,2,32,34)$

South Korea

$(32,35,36,67)$

\begin{abstract}
1 case per
20,000 people.
\end{abstract}

\begin{abstract}
Fewer than
\end{abstract}
20,000 cases.

No

Yes

Yes

Fewer than

20,000 cases.

No Yes

Yes
Rare Disease Act of the Philippines (2016): Focuses on several elements of rare disease management (diagnosis, clinical management, genetic counseling and drug research development), registry, research, and newborn screenings.

Medicines Act (Chapter 176, Section 9) (1991): Focuses on managing and encouraging the use of orphan drugs for rare disease patients. Physicians and dentist should prescribe orphan drugs for these patients if there were no substitute medications available. 10 year market exclusivity.

Orphan Drugs Guideline (2003): Medical reimbursement and research. 6 year market exclusivity.

Research Center for Rare Diseases: To do research as a single center or collaborate in clinical research networks.

Korean Biobank Project: The project would manage and collect specimens from rare disease patients, and launch a network of healthcare providers working with these patients disease or would gather bio-resources from research projects.

Rare Disease and Orphan Drug Act (2000): Grants, copay can be waived, fast track approval, protocol assistance, and medical reimbursement. 10 year market exclusivity.
No Yes
Taiwan

$(1,2,25,32,35$

$37,57,67)$
No more than 1 case per 10,000 people. encourages research that examines orphan drugs (3). The Rare Disease Act of the Philippines, approved in 2016, covers topics such as rare disease management, registry, research, and newborn screening (33). In 1991, Singapore implemented the Medicines Act (Chapter 176, Section 9) which focuses on managing, and encouraging the use of, orphan drugs (34). In 2003, South Korea created the Orphan Drugs Guideline (35) and, in 2013, the Korea Biobank Project (KBP) for rare disease (36). In Taiwan, the Rare Disease and Orphan Drug Act provides support for rare disease patients by encouraging rare disease research, and increasing awareness of rare disease $(25,37)$. Furthermore, this act also facilitates access to orphan drugs $(35,37)$. 
Table 4. Rare disease plans, legislation, programs or strategies in Latin American Countries

\begin{tabular}{|c|c|c|c|c|c|}
\hline Country & $\begin{array}{l}\text { Definition of } \\
\text { rare disease }\end{array}$ & $\begin{array}{l}\text { National } \\
\text { Plan }\end{array}$ & Legislation & $\begin{array}{l}\text { Program } \\
\text { or Strategy }\end{array}$ & Highlights \\
\hline $\begin{array}{l}\text { Argentina } \\
(25,38,39)\end{array}$ & $\begin{array}{c}\text { EU } \\
\text { Definition }\end{array}$ & No & Yes & Yes & $\begin{array}{l}\text { Law } 26.689 \text { (2011): Intended to help rare disease patients and their } \\
\text { caregivers by promoting the development of patient registries and } \\
\text { screening programs, and educational and social support activities. }\end{array}$ \\
\hline $\begin{array}{l}\text { Brazil } \\
(25,39,40)\end{array}$ & $\begin{array}{l}\text { No more than } \\
65 \text { cases per } \\
100,000 \text { people. }\end{array}$ & No & Yes & Yes & $\begin{array}{l}\text { "National Policy for Rare Diseases"(2014): Includes equal } \\
\text { healthcare services, create care guidelines for these patients at every } \\
\text { stage of a Unified Health System care, offers comprehensive care in } \\
\text { the Health Care Network, improves universal and regulated access for } \\
\text { rare disease patients, ensures access to care, and quality healthcare. }\end{array}$ \\
\hline $\begin{array}{l}\text { Chile } \\
(39)\end{array}$ & $\begin{array}{c}\text { EU } \\
\text { Definition }\end{array}$ & No & Yes & N/A & $\begin{array}{l}\text { The Ricarte Soto law aims at providing funding for care of rare } \\
\text { disease patients. It assigned a grant of } 200 \text { billion pesos for } 4 \text { years. }\end{array}$ \\
\hline $\begin{array}{l}\text { Colombia } \\
(39,41,72)\end{array}$ & $\begin{array}{l}1 \text { case per } \\
5,000 \text { people. }\end{array}$ & No & Yes & N/A & $\begin{array}{l}\text { Law } 1392 \text { (2010): Identifies the lack of orphan drugs as a health } \\
\text { issue impacting the healthcare system. Considers social protection } \\
\text { policies. It contemplates creating a registry for rare disease patients } \\
\text { and collaborating globally for research. }\end{array}$ \\
\hline $\begin{array}{l}\text { Mexico } \\
(25,39)\end{array}$ & $\begin{array}{c}\text { EU } \\
\text { Definition }\end{array}$ & No & Yes & No & $\begin{array}{l}\text { Article } 224 \text { revision (2012): Recognizes orphan drugs and their } \\
\text { treatments. Ministry of Health may enforce market authorization, no } \\
\text { rules for market exclusivity. }\end{array}$ \\
\hline $\begin{array}{l}\text { Peru } \\
(38,39)\end{array}$ & $\begin{array}{c}\text { No } \\
\text { Definition }\end{array}$ & No & Yes & N/A & $\begin{array}{l}\text { Law } 29698 \text { (2011): Includes diagnosis, surveillance, prevention, care } \\
\text { and rehabilitation. }\end{array}$ \\
\hline
\end{tabular}

\subsection{Latin America}

As seen in Table 4, our scoping review yielded publications from six countries in the Latin America region. The literature shows that Argentina, Chile and Mexico have adopted the proportion of cases in a population to define rare diseases. Brazil and Colombia have their own definitions, and Peru does not have a definition of rare disease in the document found for this review. None of the publications retrieved indicated whether or not any of the six Latin American countries had a national plan (explicit priorities, timetable, and a budget) for rare diseases. However, the literature revealed a number of legal approaches in Central and South America. Argentina implemented legislation in 2011 to aid patients with rare diseases and their caregivers $(38,39)$. Brazil created the "National Policy for Rare Diseases" in 2014 aimed at decreasing morbidity and mortality and increasing quality of life for patients with rare diseases $(39,40)$. Also, this policy called for the establishment of reference treatment centers that would provide genetic testing and counseling $(25,40)$. Recently, Chile approved a law to provide funding for the care of patients with rare diseases (39), and Colombia approved a law in 2010 that identified rare disease as a public health issue $(39,41)$. Mexico's legislation for rare disease was a revision to the general health law that authorized Seguro Popular, a national health insurance institution, to provide health insurance coverage and access to orphan drugs for Mexican patients (39). Finally, Peru passed legislation for rare diseases in 2011. This law covers from diagnosis to rehabilitation of patients with rare diseases $(38,39)$.

\section{Discussion}

For this review, we searched the academic literature for articles about national plans, polices, legislation, strategies and programs for rare diseases from countries around the world. For the study period (2000-2017), we found 56 eligible publications on these subjects from 23 countries organized into four large geographic regions (Canada and the US, Europe, Asian-Pacific countries, and Latin American countries). Of these four regions, the publications reviewed suggest that the countries from the EU presented the most unified legislative approach to rare diseases. For example, the reports for the eight European countries indicate that all of them have adopted a common definition of rare diseases and have developed national plans, laws, and programs or strategies for these diseases. Reports reviewed for the countries within the other three regions indicate that none of these countries has developed a national plan for rare diseases with explicit objectives, a timeline and a budget; however, most countries in these regions appear to have laws and programs or strategies in place for these diseases. Further, according to the literature reviewed, even within a region, the definition of a rare disease varies widely from country to country. In general, our scoping review demonstrates that the legislative approach from all 23 countries seeks to promote the development of, and access to, orphan drugs to facilitate research on rare diseases, to stimulate the development of programs for screening, diagnosis, and registries, and to foster international 


\section{collaborations.}

Previously, we mentioned studies highlighting the coherent approach of the EU to rare diseases $(16,19,20)$, including countries from Eastern Europe (42). Other studies have focused on the comparison of specific laws among multiple countries and regions; for example, laws related to facilitating treatments with orphan drugs (1) or laws seeking to address the multiple needs of patients with rare diseases (25). Our scoping review was specifically designed to identify publications in the academic literature, for the past 18 years, about countries with existing or contemplated national plans, laws, or programs/strategies related to rare diseases. Together, the studies we found indicate that legislation is a widespread approach to addressing the care of patients with rare diseases in populations. Nevertheless, for the period of our research, we found no evidence published in English of the use of this approach in vast areas of the world, such as Africa, India, and Russia.

The enactment of legislation to address the collective needs of patients with rare diseases can vary from country to country and follow a complex path. It requires that a variety of elements are in place not only to promote the passing of a law but to follow through with its implementation. For example, the US Orphan Drug Act of 1983 and its implementation resulted from the combined efforts of patient advocacy groups, medical researchers, healthcare providers, medical associations, government agencies, legislators, and the pharmaceutical industry (43). With the help of political and economic treaties, which have facilitated the creation of a common system of laws, the countries of the EU have taken government action for rare diseases one step further by including not only treatments and drugs but also timely diagnosis, access to care, and social support for patients with rare diseases in a multinational setting (25). Our compilation also identified multi-country regions with a less cohesive approach to rare diseases than the EU approach. Among the publications that we found, one discusses Latin American as one example of such regions (44).

Our compilation highlighted wide variation in government policy approaches to rare diseases around the world, from incipient to comprehensive. This variation has also been noted in another publication (1) but here we have included the definition of rare diseases found in the literature as a key feature for comparison. We found that these definitions vary widely among countries, even among countries with well-established plans and strategies. This variation, which is much wider than the differences in definitions described in this report (45), could be an obstacle to the integration of national plans into larger international plans. Researchers on rare diseases have emphasized the need for the integration of rare disease plans and studies into international consortiums. This would replace the fragmented approach currently in place with a more coordinated effort that would include larger numbers of patients and caregivers (46-48).

Because we only used English keywords and a limited period for the search, the key limitations of this study are that our results were restricted to documents and journal articles published in the last 18 years that were either completely written in English or had informative summaries written in English; therefore, we captured only a sample of all existing national laws or national law-based approaches to rare diseases. Other limitations include that we did not examine the actual pieces of legislation, our scoping review is based only on documents and articles that describe these pieces of legislation for the scientific community or for the general public. Finally, our search did not distinguish between proposed and enacted legislation; although, most of the publications selected for this exploratory review were about laws already in place, some of them for decades.

In conclusion, the specific creation of laws on rare diseases appears to be a common approach to providing care and support to individuals affected by these diseases, who are few and scattered over large national or international regions. The obstacles to this approach are many, but some countries and regions have made great advances in integrating into their legal system the view that rare diseases collectively deserve public health attention. Future research should bring attention to the evaluation of national or multinational enacted laws on rare diseases, in particular the ones enacted decades ago, to formally ascertain the extent to which the intention of these laws has been fulfilled.

\section{Acknowledgements}

Neil Khosla would like to thank Oak Ridge Institute for Science and Education (ORISE) for its financial support and Dr. Pangaja Paramsothy for her mentorship and guidance.

\section{References}

1. Gammie T, Lu CY, Babar ZU. Access to Orphan Drugs: A Comprehensive Review of Legislations, Regulations and Policies in 35 Countries. PLoS One. 2015; 10:e0140002.

2. Franco P. Orphan drugs: the regulatory environment. Drug Discov Today. 2013; 18:163-172.

3. van Weely S, Leufkens HGM. World Health Organization. Update on 2004 Background Paper, BP 6.19 Rare Diseases. http://www.who.int/medicines/areas/priority_medicines/ BP6_19Rare.pdf (accessed July 27, 2018).

4. Eurordis. About Rare Diseases. https://www.eurordis.org/ about-rare-diseases (accessed July 27, 2018).

5. Forman J, Taruscio D, Llera VA, Barrera LA, Coté TR, Edfjäll C, Gavhed D, Haffner ME, Nishimura Y, Posada M, Tambuyzer E, Groft SC, Henter JI; International Conference for Rare Diseases and Orphan Drugs (ICORD). The need for worldwide policy and action plans for rare diseases. Acta Paediatr. 2012; 101:805-807.

6. Shire. Rare Disease Impact Report: Insights from patients and the medical community. https://globalgenes.org/wp- 
content/uploads/2013/04/ShireReport-1.pdf (accessed July 27, 2018).

7. Ouyang L, Grosse SD, Armour BS, Waitzman NJ. Health care expenditures of children and adults with spina bifida in a privately insured U.S. population. Birth Defects Res A Clin Mol Teratol. 2007; 79:552-558.

8. Hadjivasiliou A. EvaluatePharma. Orphan Drug Report 2014. http://info.evaluategroup.com/rs/evaluatepharmaltd/ images/2014OD.pdf (accessed July 27, 2018).

9. Boström K, Nätterlund BS, Ahlström G. Sickness impact in people with muscular dystrophy: a longitudinal study over 10 years. Clin Rehabil. 2005; 19:686-694.

10. Cheung RY, Cohen JC, Illingworth P. Orphan drug policies: implications for the United States, Canada, and developing countries. Health Law J. 2004; 12:183-200.

11. GovTrack. H.R. 717 (107th): MD-CARE Act. https://www. govtrack.us/congress/bills/107/hr717/text (accessed July 27, 2018).

12. Mendell JR, Csimma C, McDonald CM, Escolar DM, Janis S, Porter JD, Hesterlee SE, Howell RR. Challenges in drug development for muscle disease: A stakeholders' meeting. Muscle Nerve. 2007; 35:8-16.

13. National Archives and Records Administration. Final Rule. 21 CFR Parts 136, 137, and 139. Fed Regist. 1996; 61:8781-8789.

14. Williams J, Mai CT, Mulinare J, Isenburg J, Flood TJ, Ethen M, Frohnert B, Kirby RS; Centers for Disease Control and Prevention. Updated Estimates of Neural Tube Defects Prevented by Mandatory Folic Acid Fortification - United States, 1995-2011. MMWR Morb Mortal Wkly Rep. 2015; 64:1-5.

15. Food Fortification Initiative. Global Progress of Industrially Milled Cereal Grains. http://ffinetwork.org/ global_progress/index.php (accessed July 27, 2018).

16. Taruscio D, Vittozzi L, Stefanov R. National Plans and Strategies on Rare Diseases in Europe. In: Advances in Experimental Medicine and Biology (Posada de la Paz M, Groft S, eds.). Springer Netherlands, Dordrecht, Netherlands, 2010; pp. 475-491.

17. Rodwell C, Aymé S. Rare disease policies to improve care for patients in Europe. Biochim Biophys Acta. 2015; 1852:2329-2335.

18. Commission of the European Communities. Communication from the Commission to the European Parliament, the Council, the European Economic and Social Committee and the Committee of the Regions on Rare diseases: Europe's challenges. http://ec.europa. eu/health/ph threats/non com/docs/rare com en.pdf (accessed July 27, 2018).

19. Moliner AM, Waligóra J. The European union policy in the field of rare diseases. Public Health Genomics. 2013; 16:268-277.

20. Moliner AM, Waligóra J. The European Union Policy in the Field of Rare Diseases. In: Rare Diseases Epidemiology: Update and Overview (Posada de la Paz M, Taruscio D, Groft SC, eds.). Springer International Publishing, Cham, Switzerland, 2017; pp. 561-587.

21. European Union. Reaching out to rare disease patients across Europe. http://ec.europa.eu/health/rare diseases/ docs/rd_booklet_2011 en.pdf (accessed July 27, 2018).

22. Lee DK, Wong B. An Orphan Drug Framework (ODF) for Canada. J Popul Ther Clin Pharmacol. 2014; 21:e42-46.

23. Rare Alliance Canada. Now is the Time: A Strategy for Rare Diseases is a Strategy for all Canadians. http:// www.rarealliancecanada.org/pdf/CORD Canada $R D$
Strategy 22May15.pdf (accessed July 27, 2018)

24. McMillan HJ, Campbell C. We need a "made in Canada" orphan drug framework. CMAJ. 2017; 189:E1274-E1275.

25. Dharssi S, Wong-Rieger D, Harold M, Terry S. Review of 11 national policies for rare diseases in the context of key patient needs. Orphanet J Rare Dis. 2017; 12:63.

26. Balasubramanian G, Morampudi S, Chhabra P, Gowda A, Zomorodi B. An overview of Compassionate Use Programs in the European Union member states. Intractable Rare Dis Res. 2016; 5:244-254.

27. Hyry HI, Manuel J, Cox TM, Roos JC. Compassionate use of orphan drugs. Orphanet J Rare Dis. 2015; 10:100.

28. Denis A, Mergaert L, Fostier C, Cleemput I, Simoens S. A comparative study of European rare disease and orphan drug markets. Health Policy. 2010; 97:173-179.

29. Rare Voices Australia. Orphan Drugs Fact Sheet. http:// rva.blob.core.windows.net/assets/uploads/files/Orphan Drugs_Fact_Sheet.pdf (accessed July 27, 2018).

30. Cui Y, Zhou X, Han J. China launched a pilot project to improve its rare disease healthcare levels. Orphanet J Rare Dis. 2014; 9:14.

31. Song P, He J, Li F, Jin C. Innovative measures to combat rare diseases in China: The national rare diseases registry system, larger-scale clinical cohort studies, and studies in combination with precision medicine research. Intractable Rare Dis Res. 2017; 6:1-5.

32. Wong Rieger D, Claxton W, Vines R, Padilla C, Tsang K, Hickinbotham L. An Asia pacific alliance for rare diseases. Patient. 2015; 8:11-17.

33. Republic of the Philippines House of Representatives. Sixteenth Congress Third Regular Session Republic Act No. 10747. An Act Promulgating a Comprehensive Policy in Addressing the Needs of Persons with Rare Disease. http://www.congress.gov.ph/legisdocs/ra_16/RA10747.pdf (accessed July 27, 2018).

34. Singapore Statutes Online. Medicines Act (Chapter 176, Section 9) Medicines (Orphan Drugs), (Exemption) Order, G.N. No. S 470/1991, Revised Edition 2005. https://sso. agc.gov.sg/SL/MA1975-OR12?DocDate $=20050331 \&$ Vali $d$ Date $=20160122 \&$ TransactionDate $=20160122$ (accessed July 30, 2018)

35. Song P, Gao J, Inagaki Y, Kokudo N, Tang W. Rare diseases, orphan drugs, and their regulation in Asia: Current status and future perspectives. Intractable Rare Dis Res. 2012; 1:3-9.

36. Park O, Cho SY, Shin SY, Park J-S, Kim J, Han B-G. A strategic plan for the second phase (2013-2015) of the Korea biobank project. Osong Public Health Res Perspect. 2013; 4:107-116.

37. Orphanet. How specific legislation for rare diseases and orphan drugs is changing life for some patients in Taiwan. http://www.orpha.net/actor/EuropaNews/2009/doc/Taiwan. $p d f$ (accessed July 30, 2018).

38. CheckOrphan. Argentina and Peru making progress with new rare disease laws legislated in both countries. http:// www.checkorphan.org/news/argentina-and-peru-makingprogress-with-new-rare-disease-laws-legislated-in-bothcountries (accessed July 30, 2018).

39. Arnold RJ, Bighash L, Bryón Nieto A, Tannus Branco de Araújo G, Gay-Molina JG, Augustovski F. The role of globalization in drug development and access to orphan drugs: orphan drug legislation in the US/EU and in Latin America. F1000Res. 2015; 4:57.

40. Passos-Bueno MR, Bertola D, Horovitz DD, de Faria Ferraz VE, Brito LA. Genetics and genomics in Brazil: A 
promising future. Mol Genet Genomic Med. 2014; 2:280291.

41. De Castro M, Restrepo CM. Genetics and Genomic Medicine in Colombia. Mol Genet Genomic Med. 2015; 3:84-91.

42. Pejcic AV, Iskrov G, Raycheva R, Stefanov R, Jakovljevic $\mathrm{MM}$. Transposition and implementation of EU rare disease policy in Eastern Europe. Expert Rev Pharmacoecon Outcomes Res. 2017; 17:557-566.

43. Dunkle M, Pines W, Saltonstall PL. Advocacy Groups and Their Role in Rare Diseases Research. In: Rare Diseases Epidemiology (Posada de la Paz M, Groft SC, eds.). Springer Netherlands, Dordrecht, 2010; pp. 515-525.

44. Chaves Restrepo A, Denis M. International Society for Pharmacoeconomics and Outcomes Research. Rare Diseases in Latin America: Challenges and opportunities for the equitable attention and proposal of Patients Organizations. http://press.ispor.org/LatinAmerica/2017/09/rare-diseasesin-latin-america-challenges-and-opportunities-for-theequitable-attention-and-proposal-of-patients-organizations/ (accessed July 30, 2018).

45. Richter T, Nestler-Parr S, Babela R, Khan ZM, Tesoro T, Molsen E, Hughes DA, International Society for Pharmacoeconomics and Outcomes Research Rare Disease Special Interest Group. Rare Disease Terminology and Definitions-A Systematic Global Review: Report of the ISPOR Rare Disease Special Interest Group. Value Health. 2015; 18:906-914.

46. Lochmüller H, Torrent I Farnell J, Le Cam Y, Jonker AH, Lau LP, Baynam G, Kaufmann P, Dawkins HJ, Lasko P, Austin CP, Boycott KM; IRDiRC Consortium Assembly. The International Rare Diseases Research Consortium: Policies and Guidelines to maximize impact. Eur J Hum Genet. 2017; 25:1293-1302.

47. Cutillo CM, Austin CP, Groft SC. A Global Approach to Rare Diseases Research and Orphan Products Development: The International Rare Diseases Research Consortium (IRDiRC). In: Rare Diseases Epidemiology: Update and Overview (Posada de la Paz M, Taruscio D, Groft SC, eds.). Springer International Publishing, Cham, Switzerland, 2017; pp. 349-369.

48. Taruscio D, Floridia G, Salvatore M, Groft SC, Gahl WA. Undiagnosed Diseases: Italy-US Collaboration and International Efforts to Tackle Rare and Common Diseases Lacking a Diagnosis. In: Rare Diseases Epidemiology: Update and Overview (Posada de la Paz M, Taruscio D, Groft SC, eds.). Springer International Publishing, Cham, Switzerland, 2017; pp. 25-38.

49. Wellman-Labadie O, Zhou Y. The US Orphan Drug Act: Rare disease research stimulator or commercial opportunity? Health Policy. 2010; 95:216-228.

50. Seoane-Vazquez E, Rodriguez-Monguio R, Szeinbach SL, Visaria J. Incentives for orphan drug research and development in the United States. Orphanet J Rare Dis. 2008; 3:33.

51. Haffner ME. History of Orphan Drug Regulation-United States and Beyond. Clin Pharmacol Ther. 2016; 100:342343.

52. Rhee TG. Policymaking for Orphan Drugs and Its Challenges. AMA J Ethics. 2015; 17:776-779.

53. Lichtenberg FR. The impact of new (orphan) drug approvals on premature mortality from rare diseases in the United States and France, 1999-2007. Eur J Health Econ. 2013; 14:41-56

54. Daniel MG, Pawlik TM, Fader AN, Esnaola NF, Makary
MA. The Orphan Drug Act: Restoring the Mission to Rare Diseases. Am J Clin Oncol. 2016; 39:210-213.

55. Groft SC, Rubinstein YR. New and evolving rare diseases research programs at the National Institutes of Health. Public Health Genomics. 2013; 16:259-267.

56. Lewis J, Snyder M, Hyatt-Knorr H. Marking 15 years of the Genetic and Rare Diseases Information Center. Transl Sci Rare Dis. 2017; 2:77-88.

57. Cheng I. Research Office Legislative Council Secretariat. Information Note: Rare disease policies in selected places. https://www.legco.gov.hk/research-publications/ english/1617in07-rare-disease-policies-in-selected-places20170317-e.pdf (accessed July 30, 2018).

58. Baldovino S, Moliner AM, Taruscio D, Daina E, Roccatello D. Rare Diseases in Europe: from a Wide to a Local Perspective. Isr Med Assoc J. 2016; 18:359-363.

59. Whyte B. EU adopts legislation to promote drug development for rare diseases. Bull World Health Organ. 2000; 78:711-711.

60. European Commission. Regulation (EC) No 141/2000 of the European Parliament and of the council of 16 December 1999 on orphan medicinal products. Official Journal of the European Communities. 2000; L18/1-L18/5.

61. EURORDIS. France - EUROPLAN National Conference Final Report. http://www.eurordis.org/sites/default/files/ flags/finalreport-france.pdf (accessed July 30, 2018).

62. UK Department of Health. The UK Strategy for Rare Diseases. https://www.gov.uk/government/uploads/system/ uploads/attachment_data/file/260562/UK_Strategy_for Rare_Diseases.pdf(accessed July 30, 2018).

63. EUROPLAN. NAMSE: German National Plan of Action for People with Rare Diseases. http://www.europlanproject. eu/DocumentationAttachment/NATIONALPLANS GERMAN_2013_en.pdf(accessed July 30, 2018).

64. Congiu ME. The Italian National Plan for Rare Diseases. Blood Transfus. 2014; 12:s614-s616.

65. EURORDIS. Spain - EUROPLAN National Conference Final Report. http://www.eurordis.org/sites/default/files/ finalreport-spain.pdf (accessed July 30, 2018).

66. Iskrov G, Miteva-Katrandzhieva T, Stefanov R. Challenges to orphan drugs access in Eastern Europe: The case of Bulgaria. Health Policy. 2012; 108:10-18.

67. Song P, Gao J, Inagaki Y, Kokudo N, Tang W. Intractable and rare diseases research in Asia. Biosci trends. 2012; 6:48-51.

68. Song P, Kokudo N. Revision of measures to combat intractable diseases in Japan: Three pillars will play an even greater role in the future. Intractable Rare Dis Res. 2013; 2:33-34.

69. Song P, Tang W, Kokudo N. Rare diseases and orphan drugs in Japan: developing multiple strategies of regulation and research. Expert Opin Orphan Drugs. 2013; 1:681-683.

70. Senate of the Philippines. Fourteenth Congress of the Republic of the Philippines Second Regular Session. Senate. SBN 3087. http://www.senate.gov.ph/ lisdata/103909260!.pdf (accessed July 30, 2018).

71. Cui Y, Han J. Defining rare diseases in China. Intractable Rare Dis Res. 2017; 6:148-149.

72. Mateus HE, Pérez AM, Mesa ML, Escobar G, Gálvez JM, Montaño JI, Ospina ML, Laissue P. A first description of the Colombian national registry for rare diseases. BMC Res Notes. 2017; 10:514.

(Received August 8, 2018; Revised August 21, 2018; Accepted September 5, 2018) 